\title{
STRATEGI PENANAMAN TAKSONOMI PEMBELAJARAN IPA PADA SISWA SEKOLAH DASAR (SD) UNTUK MEMBENTUK GENERASI LITERASI SAINS
}

\author{
Oleh : \\ I Komang Wisnu Budi Wijaya \\ Institut Hindu Dharma Negeri Denpasar \\ wisnu.budiwijaya@gmail.com
}

\begin{abstract}
The implementation of science education in Indonesia still not optimal yet. This is proven by the science literacy test which is held by PISA on 2009. The result of the test states the average value of Indonesian student's science literacy was under the average the other countries. Responding to the case, the government held a program called Gerakan Literasi Sains (science literacy movement) at family, school and society. In order to support the program, there are needed conceptualize six domains of science learning taxonomy on elementary school students. The six domains are knowledge, process, attitude, creativity, application and nature of science (NOS). The implementation strategies are learning inside classroom, outside classroom, conditioning, environment and exemplary.
\end{abstract}

Keywords : domains, education, science, literacy

\section{PENDAHULUAN}

Pada hakekatnya, sains (IPA) dipandang sebagai sebagai proses, sebagai produk dan sebagai prosedur (Donosepoetro dalam Trianto, 2010). Sebagai proses diartikan semua kegiatan ilmiah untuk menyempurnakan pengetahuan tentang alam maupun untuk menemukan pengetahuan baru. Sebagai produk diartikan sebagai hasil proses, berupa pengetahuan yang diajarkan dalam sekolah atau di luar sekolah ataupun bahan bacaan untuk penyebaran pengetahuan. Sebagai prosedur dimaksudkan adalah metodologi atau cara yang dipakai untuk mengetahui sesuatu (riset pada umumnya) yang lazim disebut metode ilmiah (Trianto, 2010).

Pembelajaran IPA di Indonesia menurut Kurikulum 2013 dilangsungkan pada jenjang sekolah dasar (SD), sekolah menengah pertama (SMP) serta sekolah menengah atas dan kejuruan (SMA/SMK). Di jenjang SD, pembelajaran IPA terintegrasi dengan pelajaran tematik pada kelas IV - VI. Pada jenjang SMP, pembelajaran IPA mendapat alokasi waktu 5 jam pelajaran per minggunya sedangkan pada jenjang SMA pembelajaran IPA dilakukan secara terpisah yaitu berupa pelajaran Biologi, Fisika dan Kimia.

Proses pembelajaran IPA di Indonesia belum optimal. Hal itu bisa dilihat berdasarkan hasil tes literasi sains yang diselenggarakan oleh PISA. Pada tahun 2009, nilai rata-rata literasi sains siswa di Indonesia sebesar 383 dan masih di bawah rata-rata yaitu sebesar 501 . Hasil tersebut menempatkan Indonesia pada peringkat ke-59 dari 65 negara yang diuji tes literasi sainsnya (Permanasari dkk, 2016) . Padahal, Literasi sains merupakan kunci utama untuk menghadapi berbagai tantangan pada abad XXI 
untuk mencukupi kebutuhan air dan makanan, pengendalian penyakit, menghasilkan energi yang cukup, dan menghadapi perubahan iklim. Hasil tersebut memberikan sinyal bahwa pembelajaran IPA di Indonesia masih perlu perbaikan.

$$
\text { Salah satu perbaikan }
$$
pembelajaran IPA yang dilakukan oleh pemerintah Indonesia adalah dengan mengadakan program Gerakan Literasi Sains. Gerakan tersebut merupakan bagian dari komponen gerakan literasi sekolah (GLS). Dengan adanya gerakan ini diharapkan seluruh komponen masyarakat memiliki kemampuan dalam memahami sains atau melek sains. Sasaran dari program Gerakan Literasi Sains adalah keluarga, sekolah dan masyarakat.

Sebagai dukungan dalam melaksakan gerakan literasi sains di SD, maka diperlukan adanya penanaman domain-domain dalam taksonomi pembelajaran IPA. Menurut Yager (1996) terdapat enam domain dalam taksonomi pembelajaran IPA yaitu pengetahuan (konsep), proses, kreatifitas, sikap ilmiah, aplikasi sains dan nature of science (NOS) (Jumantoro, 2012). Dengan ditanamkannya kelima domain tersebut pada siswa SD, maka diharapkan siswa memiliki pemahaman sains yang utuh dan membentuk generasi yang memiliki literasi sains.

\section{PEMBAHASAN}

\section{Literasi Sains}

Literasi sains dapat diartikan sebagai pengetahuan dan kecakapan ilmiah untuk mampu mengidentifikasi pertanyaan, memperoleh pengetahuan baru, menjelaskan fenomena ilmiah, serta mengambil simpulan berdasar fakta, memahami karakteristik sains, kesadaran bagaimana sains dan teknologi membentuk lingkungan alam, intelektual, dan budaya, serta kemauan untuk terlibat dan peduli terhadap isu-isu yang terkait sains (Kemdikbud, 2017). Berdasarkan definisi di atas dapat dinyatakan bahwa hal pokok dalam pengembangan literasi sains siswa adalah meliputi pengetahuan tentang sains, pengembangan sikap ilmiah dan pemahaman peserta didik bukan hanya sekedar tahu konsep sains melainkan juga mampu menerapkan kemampuan sains dalam memecahkan berbagai permasalahan dan dapat mengambil keputusan berdasarkan pertimbanganpertimbangan sains (Yuliati, 2017).

Seseorang

dikatakan memiliki literasi sains yang baik jika memiliki ciri-ciri sebagai berikut :

a. Menggunakan konsep sains, keterampilan proses dan nilai apabila mengambil keputusan dan bertanggung jawab dalam kehidupan sehari-hari.

b. Mengetahui bagaimana masyarakat mempengaruhi sains teknologi serta bagaimana sains dan teknologi mempengaruhi masyarakat

c. Mengetahui bahwa masyarakat mengontrol sains dan teknologi melalui pengolahan sumber daya alam.

d. Menyadari keterbatasan dan kegunaan sains teknologi untuk meningkatkan kesejahteraan manusia

e. Memahami sebagian besar konsep-konsep sains, hipotesis dan teori sains dan menggunakannya. 
f. Menghargai sains dan teknologi sebagai stimulus intelektual yang dimilikinya

g. Mengetahui bahwa pengetahuan ilmiah bergantung pada prosesproses inkuiri dan teori-teori.

h. Membedakan antara fakta ilmiah dan opini pribadi

i. Mengakui asal usul sains dan mengetahui bahwa pengetahuan ilmiah itu tentatif

j. Mengetahui aplikasi teknologi dan pengambilan keputusan menggunakan teknologi.

k. Memiliki pengetahuan dan pengalaman yang cukup untuk memberikan penghargaan kepada penelitian dan pengembangan teknologi

1. Mengetahui sumber-sumber informasi dari sains dan teknologi yang dipercaya dan menggunakan sumbersumber tersebut dalam pengambilan keputusan (Rustaman dalam Hartika, 2016)

\section{Domain dalam Taksonomi Pendidikan IPA}

Taksonomi pendidikan IPA terdiri dari enam domain. enam domain ini diharapkan mampu membantu siswa sekolah dasar agar memiliki kepekaan dan pemahaman yang baik terhadap IPA dan menerapkannya dalam kehidupan sehari-hari. Kelima domain yang dimaksud adalah sebagai berikut :

a. Domain Pengetahuan

$$
\text { Dalam IPA, ranah }
$$
pengetahuan terdiri dari fakta, konsep, hukum, teori dan hipotesis.
Ranah tersebut berkembang dari proses penemuan, penyempurnaan dan falsifikasi. Pada kurikulum 2013 pengetahuan digolongkan menjadi empat yaitu faktual, konseptual, prosedural dan metakognitif. Pengetahuan faktual meliputi elemen -elemen dasar yang para ahli gunakan dalam menyampaikan disiplin ilmu akademis mereka, memahaminya, dan mengaturnya secara sistematis. Pengetahuan konseptual meliputi skema-skema, model-model mental, atau teori teori eksplisit dan implisit dalam model model psikologi kognitif yang berbeda. Pengetahuan prosedural adalah "pengetahuan mengenai bagaimana" melakukan sesuatu. Pengetahuan metakognitif adalah pengetahuan mengenai kesadaran secara umum sama halnya dengan kewaspadaan dan penget ahuan tentang kesadaran pribadi seseorang (Suwarto, 2010).

\section{b. Domain proses}

Proses yang dimaksud disini adalah keterampilan proses sains. Keterampilan proses sains merupakan keseluruhan keterampilan yang terarah (baik kognitif dan psikomotor) yang dapat digunakan untuk menemukan suatu konsep atau prinsip atau teori untuk mengembangkan konsep yang telah ada sebelumnya ataupun untuk melakukan penyangkalan terhadap adanya suatu penemuan/falsifikasi (Indrawati dalam Trianto, 2010). Keterampilan proses dibagi menjadi dua jenis yaitu keterampilan proses sains dasar dan keterampilan proses sains terpadu. Keterampilan proses tingkat dasar meliputi : observasi, klasifikasi, komunikasi, pengukuran, prediksi dan inferensi. Sedangkan keterampilan proses terpadu meliputi 
menentukan variabel, menyusun tabel data, menyusun grafik, memberi hubungan variabel, memproses data, menganalisis penyelidikan, menyusun hipotesis, menentukan variabel secara operasional, merencanakan penyelidikan dan melakukan eksperimen (Funk dalam Trianto, 2010).

\section{c. Domain Kreativitas}

Kreativitas merupakan kemampuan seseorang untuk melahirkan sesuatu yang baru, baik berupa gagasan maupun karya nyata, baik dalam karya baru maupun kombinasi dengan hal-hal yang sudah ada, yang semuanya itu relatif berbeda dengan apa yang telah ada sebelumnya. Munandar mengungkapkan sifat-sifat yang menjadi ciri keterampilan berpikir kreatif yaitu kelancaran, keluwesan, keaslian dan berpikir terperinci. Kelancaran adalah kemampuan untuk memberikan berbagai respon. Keluwesan adalah kemampuan untuk mengemukakan bermacam-macam pemecahan atau pendekatan terhadap pemecahan masalah. Keaslian adalah kemampuan untuk mencetuskan gagasan dengan cara-cara yang asli. Penguraian adalah kemampuan untuk menguraikan sesuatu secara lebih terperinci.

\section{d. Domain Sikap}

Sikap yang diharapkan dalam pendidikan IPA adalah sikap ilmiah. Sikap ilmiah adalah adalah sikap tertentu yang diambil dan dikembangkan oleh ilmuwan untuk mencapai hasil yang diharapkan (Pardede dalam Hendracipta, 2016). Sikap ilmiah itu terdiri dari sikap ingin tahu, sikap ingin mendapat sesuatu yang baru, sikap tidak putus asa, sikap tidak berprasangka, sikap mawas diri, sikap bertanggung jawab, sikap berpikir bebas, sikap kedisiplinan diri (Tursinawati, 2013).

\section{e. Domain Aplikasi}

Domain aplikasi merupakan domain yang mengembangkan kepekaan terhadap semua pengalaman yang mereka hadapi dan merupakan pencerminan ide-ide yang telah mereka pelajarai dalam sains.

\section{f. Domain Nature of Science (NOS)}

Nature of Science (NOS) didefinisikan sebagai hakekat pengetahuan yang merupakan konsep yang kompleks melibatkan filosofi, sosiologi, dan historis suatu pengetahuan. Pembelajaran NOS mengacu pada epistomologi dan sosiologi pengetahuan, yaitu pengetahuan sebagai cara untuk mengetahui, atau menilai dan keyakinan yang menjadi sifat pengetahuan ilmiah (Santyasa dalam Sastradi, 2013).

\section{Strategi Penanaman Taksonomi Pembelajaran IPA}

Pada jenjang SD, strategi penanaman taksonomi pembelajaran IPA dapat dilakukan di dalam kelas pada kegiatan pembelajaran, di luar kelas, pengkondisian lingkungan dan keteladanan. Berikut adalah strategi penanaman domain-domain taksonomi pembelajaran IPA :

a. Domain Pengetahuan

Siswa SD perlu dibekali dengan pengetahuan IPA yang sesuai dengan perkembangan kognitifnya dan mampu memahaminya. Berikut adalah strategi penanaman pengetahuan IPA pada siswa SD :

$\checkmark$ Guru melakukan kegiatan pembelajaran secara bertahap 
dari materi yang termudah dan tersulit sehingga siswa menjadi lebih mudah memahami materi IPA.

$\checkmark$ Guru dalam melaksanakan pembelajaran IPA lebih berfokus pada konsep dan senantiasa memberikan penguatan dan penekanan pada hal hal yang penting. Selama ini, banyak guru yang melaksanakan pembelajaran IPA lebih berfokus pada soal latihan sehingga pemahaman siswa belum optimal.

$\checkmark$ Guru melaksanakan pembelajaran bermakna. Pembelajaran dikatakan bermakna jika siswa mampu mengaitkan berbagai konsepkonsep IPA. Banyak siswa yang masih lemah dalam mengaitkan konsep IPA dan cenderung menggangap konsep IPA berdiri sendiri dan tidak berkaitan.

$\checkmark$ Guru dalam melaksanakan pembelajaran IPA menggunakan berbagai media pembelajaran. Selama ini masih banyak guru yang melaksanakan pembelajaran IPA dengan metode ceramah dan hanya mengandalkan tutur dan kapur. Media pembelajaran berfungsi untuk meningkatkan atensi dan motivasi belajar siswa serta berperan besar dalam membantu siswa memahami konsep IPA.

$\checkmark$ Sekolah menyediakan buku dan referensi IPA yang cukup dan memadai bagi siswa.

$\checkmark$ Sekolah menyediakan fasilitas internet kepada siswa agar siswa senantiasa up-date tentang perkembangan IPA.

\section{b. Domain Proses}

Dalam rangka menanamkan keterampilan proses sains kepada siswa, hal yang dapat dilakukan adalah :

$\checkmark$ Melaksanakan kegiatan praktek (percobaan) bagi seluruh siswa. Pembelajaran IPA harus dijalankan dengan minds on (keterampilan berpikir) dan hands on (keterampilan motorik). Oleh karena itu, pembelajaran IPA harus senantiasa disertai dengan kegiatan percobaan agar siswa memiliki keterampilan proses sains.

$\checkmark$ Melaksanakan pembelajaran inkuiri/discovery.

Keterampilan proses sains tidak hanya berupa keterampilan motorik namun juga berupa keterampilan kognitif. Dengan mengikuti pembelajaran

inkuiri/discovery beberapa keterampilan proses sains siswa dapat dilatih seperti berhipotesis, interpretasi data dan memprediksi.

c. Domain Kreativitas

Cara melatih kreativitas siswa sekolah dasar adalah dengan cara :

$\checkmark$ Memberikan siswa pertanyaan divergen. Pertanyaan divergen adalah pertanyaan yang memungkinkan jawaban lebih dari satu. Dengan adanya pertanyaan divergen maka siswa akan mengalami proses brainstorming yang dapat mengasah kreativitas.

$\checkmark$ Menerapkan pola belajar siswa aktif (student centered learning). Ketika siswa dijadikan aktor utama dalam kegiatan pembelajaran maka siswa akan mendapatkan 
kebebasan dalam berkreasi melaksanakan pembelajaran. Kebebasan berkreasi adalah stimulus awal untuk membentuk siswa kreatif.

\section{d. Domain Sikap}

Membentuk sikap ilmiah pada siswa dapat dilaksanakan dengan keteladanan. Misalkan untuk sikap bertanggung jawab dan disiplin diri, haruslah para guru terlebih dahulu menunjukkan sikap tersebut kepada siswa. Sebab siswa sekolah dasar belajar melalui proses peniruan. Sistem reward juga bisa digunakan untuk mengembangkan sikap ilmiah. Contohnya dalam mengembangkan sikap rasa ingin tahu, sekolah bisa mengadakan lomba pengetahuan IPA bagi seluruh siswa.

\section{e. Domain Aplikasi}

Wawasan IPA yang telah didapatkan oleh siswa hendaknya diterapkan dalam kehidupan seharihari. Cara melatih domain aplikasi konsep adalah dengan cara senantiasa memberikan contoh dalam kehidupan sehari-hari terkait dengan konsep IPA yang dipelajari. Selain itu, penerapan konsep IPA yang telah dipelajari perlu juga dilakukan. Misalnya setelah siswa mempelajari materi perkembangbiakan tumbuhan, siswa diajak untuk menanam sebuah tanaman dengan teknik setek dan cangkok.

\section{f. Domain Nature of Science (NOS) \\ Mengembangkan domain} NOS pada siswa sekolah dasar dapat dilakukan dengan menerapkan pembelajaran berorientasi NOS. Pembelajaran berorientasi NOS (Nature of Science) memiliki enam langkah utama, yaitu: (1) background readings, (2) case study discussions, (3) inquiry lessons, (4) inquiry labs, (5) historical studies, (6) multiple assesments. Pada langkah background readings, siswa diajak membaca buku dan/atau artikel fisika dan membuat laporan mengenai suatu bab ataupun materi tertentu, sehingga mereka dapat menyusun latar belakang pembelajaran yang akan dilakukan. Buku dan/atau artikel yang di baca oleh siswa diupayakan agar sesuai dengan jenis pengetahuan yang dipelajari. Kemudian setelah itu dilanjutkan dengan tahap case study discussions yaitu siswa mengajukan masalah dan pertanyaan terkait buku yang telah dipelajari. Pada tahap inquiry lessons dan inquiry labs siswa melakukan studi kepustakaan atau praktek untuk mencari jawaban atas permasalahan yang diajukan. Pada tahap historical studies siswa didorong untuk menyajikan deskripsi tentang manfaat pembelajaran yang dilakukan. Terakhir pada tahap multiple assesments, guru melakukan penilaian otentik terhadap siswa (Wenning, 2006).

\section{PENUTUP}

Berdasarkan uraian pembahasan tersebut dapat disimpulkan bahwa penanaman domain taksonomi pembelajaran IPA sangat menunjang kesuksesan gerakan literasi sains untuk siswa sekolah dasar. Penanaman domain taksonomi pembelajaran IPA dapat dilakukan dengan kegiatan pembelajaran di dalam kelas, pembelajaran di luar kelas, pengkondisian lingkungan dan keteladanan. Untuk mengoptimalkan hal tersebut diperlukan kerjasama yang sinergis antara orang tua siswa, warga sekolah dan masyarakat. 
Daftar Pustaka

Hartika. 2016. Profil Kompetensi Literasi Sains Siswa Berdasarkan The Programme for International Student Assesment (PISA) Pada Konten Biologi. Skripsi. Bandar Lampung : Fakultas Keguruan dan Ilmu Pendidikan Universitas Lampung.

Hendracipta, N. 2016. Menumbuhkan Sikap Ilmiah Siswa Sekolah Dasar Melalui Pembelajaran IPA Berbasis Inkuiri. JPSD Vol.2 No. 1 Maret 2016

Jumantoro. 2012. Pengaruh Model Pembelajaran Sains Teknologi Masyarakat dan Lingkungan Terhadap Hasil Belajar dan Sikap Ilmiah Siswa. Diakses dari

https://media.neliti.com/media /publications/120823-IDnone.pdf tanggal 6 April 2018. Kemdikbud. 2017. Materi Pendukung Literasi Sains. Jakarta : Kementerian Pendidikan dan Kebudayaan.

Munandar, S.C.U. 1992. Mengembangkan Bakat dan Kreativitas Anak Sekolah, Petunjuk Bagi Para Guru dan Orang Tua. Jakarta : PT Gramedia Widiasarana Indonesia.

Permanasari, dkk. 2016. Membangun Literasi Sains Siswa Pada Konsep Asam Basa Melalui Pembelajaran Inkuiri Terbimbing. Jurnal Penelitian dan Pembelajaran IPA Vol. 2, No.2 Tahun 2016.

Tursinawati. 2013. Analisis Kemunculan Sikap Ilmiah Siswa dalam Pelaksanaan Percobaan Pada Pembelajaran IPA di SDN Kota Banda Aceh. Jurnal Pionir Vol. 1 No. 1 Tahun 2013.

Trianto. 2010. Model Pembelajaran Terpadu. Jakarta : PT. Bumi Aksara

Santoso, F.G.I. 2012. "Keterampilan Berpikir Kreatif Matematis dalam Pembelajaran Berbasis Masalah (PBM) Pada Siswa SMP". Tersedia pada math.mipa.uns.ac.id/.../45345 9_Revisi\%20Fransiskus\%20G atot\%20Ima...(diakses tanggal 7 Mei 2014)

Sastradi. 2013. Model Pembelajaran Berorientasi NOS (Nature of Science). Diakses dari http://mediafunia.blogspot.co.i $\mathrm{d} / 2013 / 01 /$ modelpembelajaran-berorientasinos.html tanggal 9 April 2018

Suwarto. 2010. Dimensi Pengetahuan dan Dimensi Proses Kognitif dalam Pendidikan. Jurnal Widyatama No. 1 Vol. 19 Tahun 2010

Wenning, C. J. 2006. A Framework for Teaching the Nature of Science. Journal of Physics Teacher Education Online. 3(3). 3-10. 2006.

Yuliati, Y. 2017. Literasi Sains dalam Pembelajaran IPA. Jurnal Cakrawala Pendas Vol. 3 No. 2 Edisi Juli 2017. 